\title{
Polymorphism in CYP17, GSTM1 and the progesterone receptor genes and its relationship with mammographic density
}

\author{
D. Chambo, C. Kemp, A.M.M. Costa, N.C.N. Souza and I.D.C. Guerreiro da Silva \\ Disciplina de Mastologia, Escola Paulista de Medicina, Universidade Federal de São Paulo, São Paulo, \\ SP, Brasil
}

Correspondence to: D. Chambo, Rua Constante Sodré, 1027/301, 29055-420 Vitória, ES, Brasil

Fax: +55-27-3227-6455. E-mail: dradanichambo@hotmail.com

\begin{abstract}
Radiologic breast density is one of the predictive factors for breast cancer and the extent of the density is directly related to postmenopause. However, some patients have dense breasts even during postmenopause. This condition may be explained by the genes that codify for the proteins involved in the biosynthesis, as well as the activity and metabolism of steroid hormones. They are polymorphic, which could explain the variations of individual hormones and, consequently, breast density. The constant need to find markers that may assist in the primary prevention of breast cancer as well as in selecting high risk patients motived this study. We determined the influence of genetic polymorphism of CYP17 (cytochrome P450c17, the gene involved in steroid hormone biosynthesis), GSTM1 (glutathione S-transferase M1, an enzyme involved in estrogen metabolism) and PROGINS (progesterone receptor), for association with high breast density. One hundred and twenty-three postmenopausal patients who were not on hormone therapy and had no clinical or mammographic breast alterations were included in the present study. The results of this study reveal that there was no association between dense breasts and CYP17 or GSTM1. There was a trend, which was not statistically significant $(P=0.084)$, towards the association between PROGINS polymorphism and dense breasts. However, multivariate logistic regression showed that wild-type PROGINS and mutated CYP17, taken together, resulted in a 4.87 times higher chance of having dense breasts $(P=0.030)$. In conclusion, in the present study, we were able to identify an association among polymorphisms, involved in estradiol biosyntheses as well as progesterone response, and radiological mammary density.
\end{abstract}

Key words: Mammography; 17-alpha hydroxylase steroid; Glutathione transferase; Progesterone receptor; Genetic polymorphism

Publication supported by FAPESP.

Received May 2, 2008. Accepted February 11, 2009

\section{Introduction}

Radiological breast density is influenced by the hormonal changes that occur throughout the life of women and is considered to be one of the most important independent risk factors for breast cancer (1-5). Generally, women with high breast density (more than $50 \%$ of glandular tissue) have a 4 to 6 times higher risk to develop breast cancer (4) than women with fatty breasts. While there is convincing evidence for the independent association of breast density with breast cancer risk, it is perhaps the most underestimated and underused risk factor when it comes to causal studies of breast cancer. Actually, it has not been included as a parameter in the traditional risk calculation models such as that of Gail et al. (6) and more recently in the model proposed by Rockhill et al. (7).

There have been numerous studies linking mammographic breast density to factors associated with exposure to endogenous and exogenous steroid hormones such as age, menopausal status, parity, body mass index (BMI), and the use of hormone therapy (4).

For instance, the luteal phase of the menstrual cycle exposes the breast tissue to estradiol and progesterone and this causes an increase in breast density (8). Pre- 
menopausal women also have denser breasts compared with postmenopausal women. Increase in breast density after menopause has been attributed to alterations in growth factor (9), epidemiologic factors (10) and genetic factors (11), but there is no conclusive data to support any of these. Based on the established function of endogenous steroids for maintaining and developing breast tissue, individual variation in breast density may be due, in part, to polymorphisms in steroid hormone biosynthesis, metabolism and signaling genes (3).

Recently, the genetic basis of changes in hormone levels has been recognized as an important factor for breast cancer risk. According to some studies, polymorphisms in certain genes could affect breast cancer risk through differences in breast density $(12,13)$. Recent studies have proposed that cytochrome P450c17 (CYP17, involved in biosynthesis), glutathione S-transferase M1 (GSTM1, which also has an important function in estrogen metabolism) and progesterone receptor gene polymorphism (PROGINS) are potential candidate biomarkers for breast cancer $(14,15)$. It is thus important to seek markers that assist in the identification of high-risk persons on the basis of breast density, which is determined by genetic individuality.

\section{Patients and Methods}

\section{Study population}

Eligible cases consisted of 123 women with no previous history of hormone replacement therapy, treated at the Climacteric Section, Gynecology Department at the Federal University of São Paulo from August to December

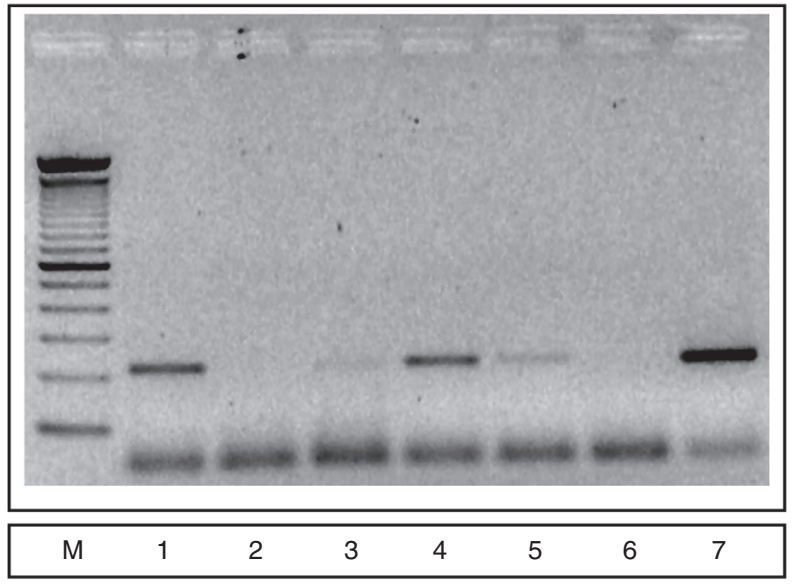

Figure 1. Gel electrophoretic pattern for polymorphism in GSTM1. Lane $M=100$-bp marker; lanes 1, 3, 4, 5, 7 = GSTM1 present in samples (268 bp); lanes 2 and $6=$ null GSTM1 samples.
2006. As inclusion criteria, no more than 5 years since the beginning of menopause, serum follicle-stimulating hormone $(\mathrm{FSH})>30 \mu \mathrm{L} / \mathrm{mL}$, estradiol $<50 \mathrm{pg} / \mathrm{mL}$, should not present hepatic, kidney and endocrine disease, nor severe hypertension, and with no family history of breast cancer and a class 1 or 2 mammogram exam (BI-RADS, Breast Imaging and Data System, American College of Radiologists). All women were selected after the approval of the research plan by the University Ethics Committee and written informed consent was obtained from all participants.

\section{Buccal swab collection and DNA extraction}

Buccal swab samples were obtained using a Cytobrush type cell collector that was rubbed against the buccal mucosa and were placed in a Falcon tube containing Tris-EDTA buffer and stored at $-80^{\circ} \mathrm{C}$. DNA extraction was performed according to the Amersham Pharmacia GFX ${ }^{\circledR}$ Kit protocol for buccal cells and quantified spectrophotometrically at 260 nm using a Genesys 5 model Spectronic spectrophotometer (Spectronic Instruments, USA).

\section{Genotyping}

Polymerase chain reaction (PCR) fragments were generated using the following primers: GSTM1 forward $(F)$ : $5^{\prime}$ GAA CTC CCT GAA AAG CTA AAG C - 3' and GSTM1 reverse (R): 5' - GTT GGG CTC AAA TAT ACG GTG G - 3; CYP17 F: 5' - CAT TCG CAC TCT GGA GTC - 3' and CYP17R: 5' - AGG CTC TTG GGG TAC TTG - 3; PROGINS F: 5' - GGC AGA AAG CAA AAT AAA AAG A - 3' and PROGINS R: 5' - AAA GTA TTT TCT TGC TAA ATG TC - 3'.

PCR was carried out using standard procedures. Briefly $20-\mu \mathrm{L}$ aliquots containing approximately $70 \mathrm{ng}$ Genomic DNA, 25 pmols primer, $1 \mathrm{X}$ reaction buffer, $100 \mu \mathrm{M}$ dNTPs and one unit of Taq polymerase. The reaction was performed for 35 cycles at $55^{\circ} \mathrm{C}$ annealing temperature to all primer sets.

After PCR amplification, the polymorphisms were assayed by restriction fragment length polymorphism. The CYP17 PCR product was incubated with 3 units of specific restriction enzyme $\mathrm{MspA} 1 \mathrm{l}\left(\mathrm{MBI}\right.$ Fermentas) at $37^{\circ} \mathrm{C}$ for $3 \mathrm{~h}$. The resulting fragments were electrophoresed on a $2 \%$ agarose gel, stained with ethidium bromide and visualized under UV (Figures 1-3).

We used only PCR to genotype subjects for GSTM1 and PROGINS. Homozygous deletion variants of GSTM1 did not result in an amplification fragment (16). On the other hand, the presence of the gene resulted in a 268-bp amplicon. The wild-type allele for PROGINS, defined as the absence of insertion according to Rowe et al. $(17,18)$, generated a 149-bp fragment and its polymorphic allele 


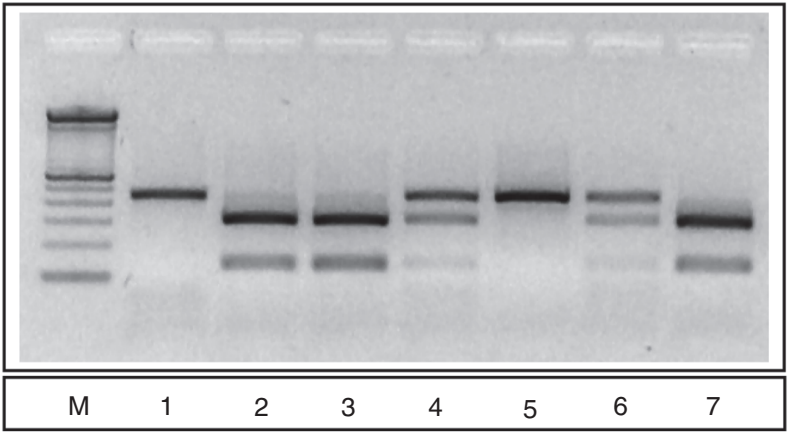

Figure 2. Gel electrophoresis showing the polymorphic patterns obtained for CYP17. Lane $M=100$-bp marker; lanes 1 and 5= wild homozygote samples for the CYP17 polymorphism (419 bp); lanes 2, 3, and $7=$ mutated homozygote samples for the CYP17 polymorphism (295 and $124 \mathrm{bp}$ ); lanes 4 and $6=$ heterozygote samples for the CYP17 polymorphism (419, 295 and $124 \mathrm{bp})$.

generated a 455-bp fragment. Alleles were classified on the basis of the presence of amplified fragments of corresponding size using standard markers.

\section{Mammograph analysis}

The mammographs were analyzed in medial-lateral view in order to visualize a greater quantity of parenchyma. The left medial-lateral view was chosen by convention. The films were assessed using subjective and objective analysis.

In the subjective part of the analysis, the mammary density was classified according to the ACR-BIRADS (19) into four categories: D1, mainly lipo-substituted breasts (0$25 \%$ of parenchymal tissue); D2, partially lipo-substituted breasts (25-50\% of parenchymal tissue); D3, moderately dense breasts $(50-75 \%$ of parenchymal tissue); D4, extremely dense breasts ( $>75 \%$ of parenchymal tissue). Due to the subjectivity associated with the method the films were assessed and classified by two independent trained observers. Kappa statistics ( $\kappa$ ) was applied, according to Landis and Koch (20), to measure the agreement between two observers. Due to the reduced number of women, the initial 4 groups (D1, D2, D3, and D4) were reduced to two groups (D1 + D2 and D3 + D4) for further analysis (see Table 1).

The objective analysis was carried out to obtain reproducible values for mammary density. The images were digitized using a CX312 T scanner (Radiographic Digital Imaging Compton, USA) and stored as tagged image file (tif) format. A tif image is composed of small descriptor blocks containing offsets into the file, which point to the actual pixel image data, and there is no loss in image quality. The digitized images were analyzed with the aid of

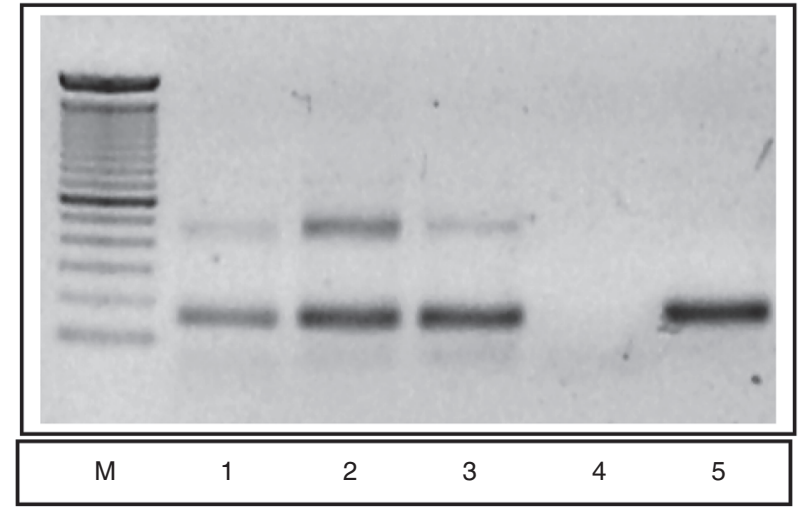

Figure 3. Gel electrophoresis showing the polymorphic patterns obtained for PROGINS. Lane $M=100$-bp marker; lanes 1, 2, and 3 = PROGINS heterozygote sample (455 and $149 \mathrm{bp}$ ); lane $4=$ negative control of the reaction; lane $5=$ wild PROGINS sample (149 bp).

Table 1. Frequency of the breast density classification according to individual observer analysis and software analysis (Photoshop) by BI-RADS criteria and two subgroups.

\begin{tabular}{lcccccccc}
\hline Category & \multicolumn{3}{c}{ BI-RADS } & & & \multicolumn{2}{c}{ New subgroups } \\
\cline { 2 - 4 } \cline { 8 - 9 } & D1 & D2 & D3 & D4 & & D1 + D2 & D3 + D4 \\
\hline Observer 1 & 35 & 46 & 27 & 8 & & 81 & 35 \\
Observer 2 & 29 & 52 & 28 & 7 & & 81 & 35 \\
Photoshop & 28 & 54 & 27 & 7 & & 82 & 34 \\
\hline
\end{tabular}

$\mathrm{D} 1=0-25 \%$ parenchymal ti * ssue; D2 $=25-50 \%$ parenchymal tissue; D3 $=50-75 \%$ parenchymal tissue; $D 4=75-100 \%$ parenchymal tissue. New subgroups: non-dense breasts (D1 + D2); dense breasts (D3 + D4). Obs = observer. Inter-rater agreement (kappa index, $\kappa$ ) was used to evaluate the agreement in the density classification: Obs $1 \times$ Obs2 (BI-RADS criteria) $\kappa=0.91$; Obs1 $x$ software (BI-RADS criteria) $\kappa=0.834$; Obs2 $\mathrm{x}$ software (BI-RADS criteria) $\kappa=0.91(\mathrm{P}<0.001$ ); Obs1 $\mathrm{x}$ Obs2 (new subgroup) $\kappa=1$; Obs $x$ software (new subgroup) $\kappa=0.942(P<$ $0.001)$.

the Photoshop 6.0 software (Figure 4). The density was calculated using the gray scale histogram tool. Mammary density was normalized using the following equation: $\mathrm{DM}=$ AD / AT x 100, where DM is the mammary density, AD is the dense area, and AT is the total area (see Table 1).

\section{Statistical analysis}

Initially, all variables were analyzed descriptively. The quantitative variables were analyzed by observation of the minimum and maximum values, and by calculation of medians, means and standard deviations. Relative and absolute frequencies were calculated for the qualitative variables. Inter-rater agreement (kappa) index was used to 

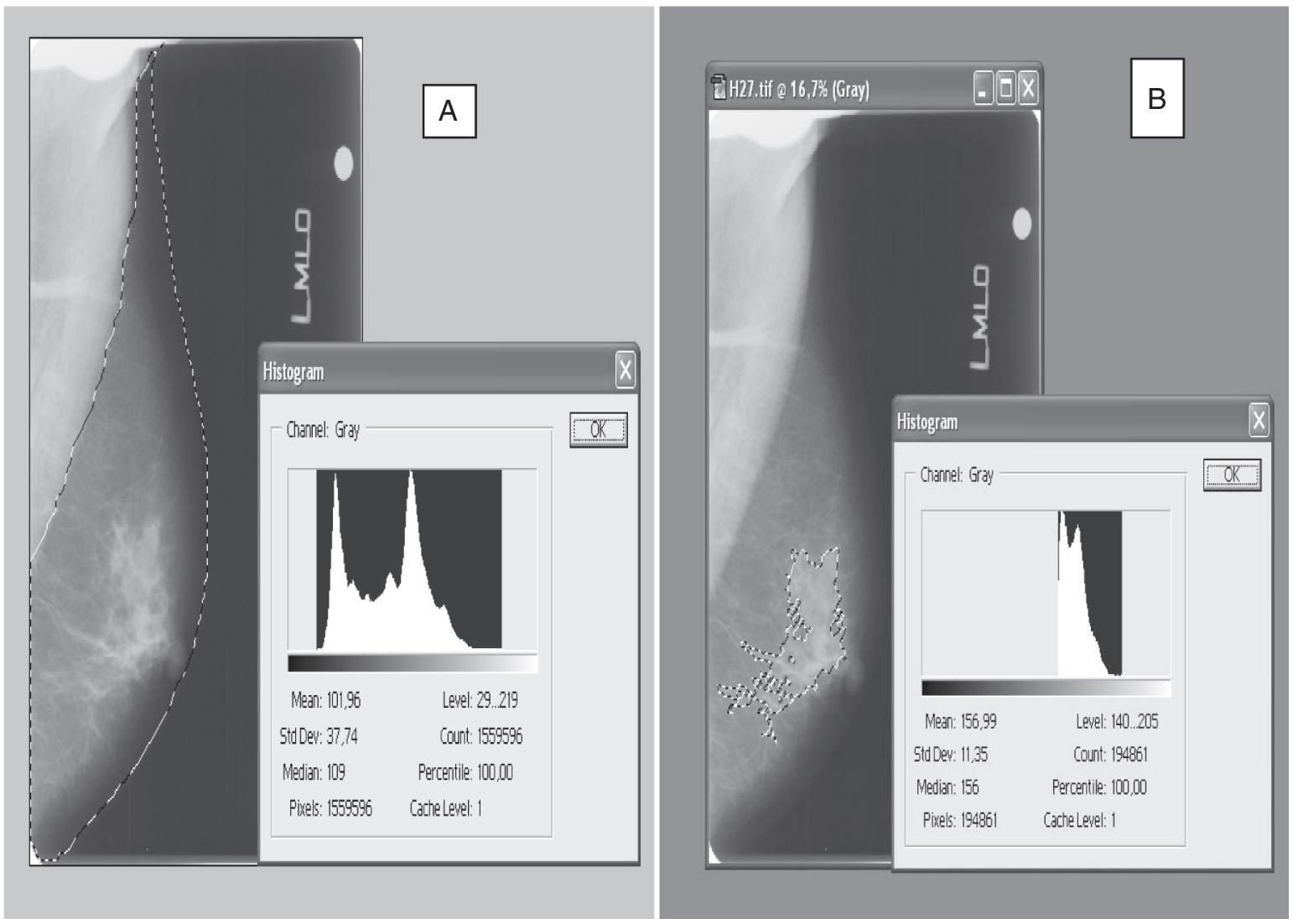

Figure 4. Breast density calculation on a lipo-substituted breast. Panel $A$, Selection of the total area of the breast, which is equivalent to $1,559,596$ pixels. Panel $B$, Selection of the dense area, which is equivalent to 194,861 pixels the gray scale. Thus, there is $12 \%$ dense area in this breast.

Table 2. Patient characteristics according to the subclassification of breast densities.

\begin{tabular}{lcc}
\hline & $\begin{array}{c}\mathrm{D} 1+\mathrm{D} 2 \\
(\mathrm{~N}=86)\end{array}$ & $\begin{array}{c}\mathrm{D} 3+\mathrm{D} 4 \\
(\mathrm{~N}=37)\end{array}$ \\
\hline Age $^{\mathrm{b}}$ & $52.45 \pm 4.49$ & $51.32 \pm 4.57$ \\
BMI $^{\mathrm{b}}$ & $28.22 \pm 4.19$ & $24.56 \pm 3.73^{*}$ \\
Smokingc $^{\mathrm{c}}$ (number of patients) & $18(20.9 \%)$ & $10(27.0 \%)$ \\
Parity $^{\mathrm{d}}$ & $3.14 \pm 1.71$ & $2.24 \pm 1.32^{*}$ \\
Age at first deliverya,b $_{\text {Breast feeding }}^{\mathrm{c}}$ & $22.84 \pm 4.60$ & $24.58 \pm 5.31$ \\
Age at menarche $^{\mathrm{b}}$ & $75(87.2 \%)$ & $31(83.8 \%)$ \\
Age at menopause $^{\mathrm{b}}$ & $13.03 \pm 1.60$ & $14.05 \pm 1.84^{*}$ \\
Time of menopause $^{\mathrm{d}}$ & $48.60 \pm 4.51$ & $47.59 \pm 4.52$ \\
Hormone influence time $^{\mathrm{b}}$ (years) & $35.85 \pm 3.35 \pm 4.60$ & $3.73 \pm 3.51$ \\
\end{tabular}

$\mathrm{D} 1=0-25 \%$ parenchymal tissue; $\mathrm{D} 2=25-50 \%$ parenchymal tissue; $\mathrm{D} 3=50-75 \%$ parenchymal tissue; $\mathrm{D} 4=75-100 \%$ parenchymal tissue; $\mathrm{D} 1$ + D2 = non-dense; $\mathrm{D} 3+\mathrm{D} 4$ = dense; $\mathrm{BMI}=$ body mass index. aseven cases of parity were equal to zero (3 cases in D1 + D2 and 4 cases in D3 + D4). Statistical analysis was performed using the ${ }^{b}$ Student $t$-test, the ${ }^{c}$ chi-square test, and the ${ }^{d}$ Mann-Whitney non-parametric test $(P<0.007)$.
Table 3. Polymorphism patterns and their distribution according to the subclassification of breast densities.

\begin{tabular}{lcr}
\hline Category & D1 + D2 (N = 86) & D3 + D4 (N = 37) \\
\hline $\begin{array}{l}\text { CYP17 } \\
\text { Heterozygote }\end{array}$ & $47(54.7 \%)$ & $18(48.7 \%)$ \\
$\quad$ Mutated & $10(11.6 \%)$ & $9(24.3 \%)$ \\
$\quad$ Wild & $29(33.7 \%)$ & $10(27.0 \%)$ \\
PROGINS & & \\
$\quad$ Heterozygote & $20(23.3 \%)$ & $4(10.8 \%)$ \\
$\quad$ Wild & $66(76.7 \%)$ & $33(89.2 \%)$ \\
GSTM1 & & \\
$\quad$ Null & $22(25.6 \%)$ & $7(18.9 \%)$ \\
Present & $64(74.4 \%)$ & $30(81.1 \%)$ \\
\hline
\end{tabular}

Data are reported as number with percent in parentheses. D1 + $\mathrm{D} 2$ = non-dense; D3 + D4 = dense; CYP17 = cytochrome $\mathrm{P} 450 \mathrm{c} 17$; PROGINS = progesterone receptor gene polymorphism; GSTM1 = glutathione S-transferase M1. 
evaluate the agreement in the density classification. Student $t$-test was used to analyze the equality hypothesis between the two groups. When the supposition of normality of the data was rejected, the Mann-Whitney non-parametric test was used. The chi-square test was used to test the group homogeneity of proportions. The logistic regression model was used for the multivariate study of the factors. Through these means, the confidence intervals for odds ratio were obtained. The significance level used for the tests was $5 \%$.

\section{Results}

The characteristics of the women who participated in the study are summarized in Table 2. BMI, parity and age at menarche were statistically significant when was compared between groups of mammary density. Patterns of polymorphisms are illustrated in Figures 1, 2, 3 and the results of the association between polymorphisms and mammary density are presented in Table 3. Polymorphisms in CYP17 and GSTM1 are clearly not associated with breast density. This result is different from the literature that afirms that GSTM1 homozygous deletion was associated with high mammographic density (21) but agrees with CYP17 findings in which Warren et al. (22) studied 15 single nucleotide polymorphisms (SNP) in the CYP17, CYP19, EDH17B2, SHBG, COMT, and CYP1B1 genes and none of the SNPs, including those shown previously to be associated with estradiol or SHBG, showed significant associations with breast density. The same thing occurred with PROGINS when analyzed in a isolated form $(\mathrm{P}=$ $0.110)$. However, the multivariate logistic regression analysis model built using the variables BMI, PROGINS, parity, and age at menarche helped delineate the association of these variables to breast density. The results of the regression analysis are summarized in Table 4. Analysis of the variables also revealed that there was a negative correlation between BMI and breast density as well as between parity and breast density, thus the greater the BMI and parity, the lesser the probability of dense breast. Age at menarche, on the other hand, presented a positive correlation with breast density, i.e., the greater the age at menarche, the greater the probability of dense breasts. The association of PROGINS with breast density was not significant. Amplification of the sample will be necessary to define its predictive power.

To further understand the multi-factorial nature of breast density, additional variables in the form of the three studied polymorphisms (CYP17, GSTM1, and PROGINS) were included in the regression model. The results are summarized in Table 5.
An additional analysis including both wild-type PROGINS and the mutated CYP17 was created and built into the model. The odds ratio values, following the use of this new genotype association, are summarized in Table 6.

Table 4. Multivariate logistic regression analysis model of BMI, PROGINS, parity, and age at menarche variable for dense breast.

\begin{tabular}{lcc}
\hline Variables & Odds ratio & $95 \% \mathrm{Cl}$ \\
\hline BMI & 0.81 & $0.71-0.91^{*}$ \\
PROGINS & 0.31 & $0.08-1.17$ \\
Parity & 0.63 & $0.44-0.90^{*}$ \\
Age at menarche & 1.43 & $1.09-1.86^{*}$ \\
\hline
\end{tabular}

$\mathrm{BMI}=$ body mass index. $\mathrm{PROGINS}=$ progesterone receptor gene polymorphism.

Table 5. Odds ratio, 95\% confidence interval and $P$ value of the multivariate logistic and regression model for dense breast, including the statistically relevant variables (BMI, parity, age at menarche).

\begin{tabular}{lllr}
\hline Variables & $\begin{array}{l}\text { Odds } \\
\text { ratio }\end{array}$ & $95 \% \mathrm{Cl}$ & $\mathrm{P}$ \\
& 0.80 & $0.70-0.90$ & $<0.001$ \\
BMI & 0.25 & $0.06-1.06$ & 0.060 \\
PROGINS (wild x heterozygote) & 1.09 & $0.34-3.52$ & 0.881 \\
GSTM1 (null x present) & 1.36 & $0.47-3.96$ & 0.568 \\
CYP17 (wild x heterozygote) & 4.02 & $0.94-17.20$ & 0.061 \\
CYP17 (wild x mutated) & 0.62 & $0.43-0.89$ & 0.011 \\
Parity & 1.40 & $1.06-1.85$ & 0.018 \\
Age at menarche & & & \\
\hline
\end{tabular}

The three possible gene polymorphism patterns are included. $\mathrm{BMI}=$ body mass index; $\mathrm{PROGINS}=$ progesterone receptor gene polymorphism; GSTM1 = glutathione S-transferase M1; CYP17 = cytochrome P450c17.

Table 6. Odds ratio, 95\% confidence interval and $P$ value of the multivariate logistic and regression model, including the statistically relevant variables and the simultaneous presence of wild PROGINS and mutated CYP17.

\begin{tabular}{lccc}
\hline Variables & Odds ratio & $95 \% \mathrm{Cl}$ & $\mathrm{P}$ \\
\hline BMI & 0.79 & $0.70-0.90$ & $<0.001$ \\
Parity & 0.64 & $0.45-0.91$ & 0.014 \\
Age at menarche & 1.39 & $1.05-1.83$ & 0.020 \\
PROGINS and CYP17 & 4.87 & $1.16-20.39$ & 0.030 \\
Others* $^{*}$ & 1.00 & - & - \\
\hline
\end{tabular}

$\mathrm{BMI}=$ body mass index; PROGINS = progesterone receptor gene polymorphism; CYP17 = cytochrome P450c17. *Wild and mutated. 
The results are indicative of the fact that women harboring wild-type PROGINS and mutated CYP17 have a 4.87 chance to exhibit dense breasts compared with those who do not present this combination.

\section{Discussion}

In the present study, we were able to identify genetic variations in CYP17 and in progesterone receptor genes as potential markers for high radiological breast density in menopausal women when both were present. We also confirmed a previous positive association of high breast density and variables such as BMI, parity and age at first birth. Almost $70 \%$ of our sample presented non-dense breasts after 1-5 years of menopause status. These women, besides having higher BMI and greater parity, also had younger age at the first birth, which is a stronger variable in postmenopausal women (23). From the genetic point of view, there are conflicting results in the literature regarding breast density. Indeed, several other researchers have found discrepant results when trying to associate breast density with genetic variables $(13,14,24)$.

To the best of our knowledge, we are the first to find associations between progesterone receptor variants, CYP17 and radiologic breast density. Indeed, our results regarding the progesterone receptor gene might be one of the reasons why, in the postmenopausal estrogen/progestin interventions (PEPI) trials (25), it was found that $8 \%$ of estrogen-only users and about $19-24 \%$ of estrogen-progestin users had increased breast density, compared with a $2 \%$ increase in the placebo group. Their results of a 13fold increased risk for denser breasts clearly points to the importance of progesterone.

Progesterone therapy has been shown to vary based on the accessibility of the functional progesterone receptor (PR) (26). The PR polymorphism, known as PROGINS, consists of a 306-bp Alu insertion in intron $G$ in the hormone-binding domain encoding region of the gene (18).

\section{References}

1. Wolfe JN. Breast patterns as an index of risk for developing breast cancer. AJR Am J Roentgenol 1976; 126: 11301137.

2. Saftlas AF, Szklo M. Mammographic parenchymal patterns and breast cancer risk. Epidemiol Rev 1987; 9: 146-174

3. Genetic deteminants of mammographic density. Breast Cancer Res (on line) http://breast-cancerresearch.com/content/4/3/R5; 2002

4. Haiman CA, Hankinson SE, De Vivo I, Guillemette C, Ishibe $\mathrm{N}$, Hunter DJ, et al. Polymorphisms in steroid hormone
Human progesterone receptor (hPR) gene uses separate promoters and translation start sites to produce two isoforms hPR-A and hPR-B with varying transcriptional activity and the presence of PROGINS might be associated with an imbalance in the production of these two isoforms (26). We speculate that these results support the view that the presence of the hPR-A isoform could lead to a greater mitogenic action of progesterone resulting in greater breast density (25).

Glutathione S-transferases (GSTs) that catalyze glutathione-mediated reduction of exogenous and endogenous electrophiles have broad and sometimes overlapping substrate specificities (27). The other focus of our study was the polymorphism located in the CYP17 gene, which is responsible for the production of one enzyme involved in the biosynthesis of steroid hormones. This simple $\mathrm{T} \rightarrow \mathrm{C}$ change in the 5' promoter region of CYP17 is reported to increase estradiol levels and has also been investigated for its risk in breast cancer development, with conflicting results (28). As an isolated finding, our results did not identify CYP17 as a marker for breast density; however, after multivariate logistic regression, our results identified wild-type PROGINS and the polymorphic form of CYP17 as potential markers to determine a 4.87 greater chance of having dense breasts $(P=0.03)$. According to these findings, we suggest that breast density might be related to an increased estradiol biosynthesis, due to CYP17 polymorphism, followed by a strong progesterone action determined by the hPR-A isoform. This biochemical scenario would then be responsible for an increase of breast density.

The results of our study suggest the importance of using genetic analysis in the determination of breast density and that there is a complex picture of the associations between genes. It could open up new approaches to identifying patients at risk and in the future, it might permit a more rational choice for selecting patients who would really benefit from hormonal therapy. pathway genes and mammographic density. Breast Cancer Res Treat 2003; 77: 27-36.

5. Lai JH, Vesprini D, Zhang W, Yaffe MJ, Pollak M, Narod SA. A polymorphic locus in the promoter region of the IGFBP3 gene is related to mammographic breast density. Cancer Epidemiol Biomarkers Prev 2004; 13: 573-582.

6. Gail MH, Brinton LA, Byar DP, Corle DK, Green SB, Schairer $\mathrm{C}$, et al. Projecting individualized probabilities of developing breast cancer for white females who are being examined annually. J Natl Cancer Inst 1989; 81: 1879-1886. 
7. Rockhill B, Byrne C, Rosner B, Louie MM, Colditz G. Breast cancer risk prediction with a log-incidence model: evaluation of accuracy. J Clin Epidemiol 2003; 56: 856-861.

8. Ursin G, Parisky YR, Pike MC, Spicer DV. Mammographic density changes during the menstrual cycle. Cancer Epidemiol Biomarkers Prev 2001; 10: 141-142.

9. Diorio C, Pollak M, Byrne C, Masse B, Hebert-Croteau N, Yaffe $M$, et al. Insulin-like growth factor-I, IGF-binding protein-3, and mammographic breast density. Cancer Epidemiol Biomarkers Prev 2005; 14: 1065-1073.

10. van Gils $\mathrm{CH}$, Hendriks JH, Otten JD, Holland R, Verbeek $\mathrm{AL}$. Parity and mammographic breast density in relation to breast cancer risk: indication of interaction. Eur J Cancer Prev 2000; 9: 105-111.

11. Pankow JS, Vachon CM, Kuni CC, King RA, Arnett DK, Grabrick DM, et al. Genetic analysis of mammographic breast density in adult women: evidence of a gene effect. $J$ Natl Cancer Inst 1997; 89: 549-556.

12. Feigelson HS, Kean-Cowdin R, Coetzee GA, Stram DO, Kolonel LN, Henderson BE. Building a multigenic model of breast cancer susceptibility: CYP17 and HSD17B1 are two important candidates. Cancer Res 2001; 61: 785-789.

13. Lillie EO, Bernstein L, Ingles SA, Gauderman WJ, Rivas GE, Gagalang V, et al. Polymorphism in the androgen receptor and mammographic density in women taking and not taking estrogen and progestin therapy. Cancer Res 2004; 64: 1237-1241.

14. Haiman CA, Bernstein L, Berg D, Ingles SA, Salane M, Ursin G. Genetic determinants of mammographic density. Breast Cancer Res 2002; 4: R5.

15. Fabjani G, Tong D, Czerwenka K, Schuster E, Speiser P, Leodolter $S$, et al. Human progesterone receptor gene polymorphism PROGINS and risk for breast cancer in Austrian women. Breast Cancer Res Treat 2002; 72: 131-137.

16. Arand M, Muhlbauer R, Hengstler J, Jager E, Fuchs J, Winkler $\mathrm{L}$, et al. A multiplex polymerase chain reaction protocol for the simultaneous analysis of the glutathione Stransferase GSTM1 and GSTT1 polymorphisms. Anal Biochem 1996; 236: 184-186.

17. Lancaster JM, Berchuck A, Carney ME, Wiseman R, Taylor JA. Progesterone receptor gene polymorphism and risk for breast and ovarian cancer. Br J Cancer 1998; 78: 277.

18. Rowe SM, Coughlan SJ, McKenna NJ, Garrett E, Kieback
DG, Carney DN, et al. Ovarian carcinoma-associated Taql restriction fragment length polymorphism in intron $G$ of the progesterone receptor gene is due to an Alu sequence insertion. Cancer Res 1995; 55: 2743-2745.

19. American College of Radiology. Breast imaging reporting and data system (BI-RADS). Reston: American College of Radiology; 1993.

20. Landis JR, Koch GG. The measurement of observer agreement for categorical data. Biometrics 1977; 33: 159-174.

21. Morais LM, Cardoso FC, Lourenco GJ, Shinzato JY, Zeferino LC, Lima CS, et al. [Polymorphisms GSTM1 and GSTT1 and sporadic breast cancer mammographic features]. Rev Assoc Med Bras 2008; 54: 61-66.

22. Warren R, Skinner J, Sala E, Denton E, Dowsett M, Folkerd $\mathrm{E}$, et al. Associations among mammographic density, circulating sex hormones, and polymorphisms in sex hormone metabolism genes in postmenopausal women. Cancer Epidemiol Biomarkers Prev 2006; 15: 1502-1508.

23. El-Bastawissi AY, White E, Mandelson MT, Taplin SH. Reproductive and hormonal factors associated with mammographic breast density by age (United States). Cancer Causes Control 2000; 11: 955-963.

24. Maskarinec G, Lurie G, Williams AE, Le Marchand L. An investigation of mammographic density and gene variants in healthy women. Int J Cancer 2004; 112: 683-688.

25. Greendale GA, Reboussin BA, Sie A, Singh HR, Olson LK, Gatewood O, et al. Effects of estrogen and estrogen-progestin on mammographic parenchymal density. Postmenopausal Estrogen/Progestin Interventions (PEPI) Investigators. Ann Intern Med 1999; 130: 262-269.

26. De Vivo I, Hankinson SE, Colditz GA, Hunter DJ. A functional polymorphism in the progesterone receptor gene is associated with an increase in breast cancer risk. Cancer Res 2003; 63: 5236-5238.

27. Spurdle AB, Webb PM, Purdie DM, Chen X, Green A, Chenevix-Trench G. Polymorphisms at the glutathione Stransferase GSTM1, GSTT1 and GSTP1 loci: risk of ovarian cancer by histological subtype. Carcinogenesis 2001; 22: 67-72.

28. Ye Z, Parry JM. The CYP17 MspA1 polymorphism and breast cancer risk: a meta-analysis. Mutagenesis 2002; 17: 119-126. 